Relations industrielles

Industrial Relations

\title{
The Current Industrial Relations Scene in Canada 1978, by W.D. Wood and Pradeep Kumar (Ed.), Kingston, Industrial Relations Center, Queen's University, 1978, 693 pp.
}

\section{Gérard Dion}

\section{Volume 33, numéro 4, 1978}

URI : https://id.erudit.org/iderudit/028929ar

DOI : https://doi.org/10.7202/028929ar

Aller au sommaire du numéro

Éditeur(s)

Département des relations industrielles de l'Université Laval

ISSN

0034-379X (imprimé)

1703-8138 (numérique)

Découvrir la revue

Citer ce compte rendu

Dion, G. (1978). Compte rendu de [The Current Industrial Relations Scene in Canada 1978, by W.D. Wood and Pradeep Kumar (Ed.), Kingston, Industrial Relations Center, Queen's University, 1978, 693 pp.] Relations industrielles / Industrial Relations, 33(4), 718-718. https://doi.org/10.7202/028929ar

Tous droits réservés $\mathbb{~}$ Département des relations industrielles de l'Université Laval, 1978
Ce document est protégé par la loi sur le droit d'auteur. L’utilisation des services d'Érudit (y compris la reproduction) est assujettie à sa politique d'utilisation que vous pouvez consulter en ligne.

https://apropos.erudit.org/fr/usagers/politique-dutilisation/ 
Cet ouvrage, qui n'a vraiment rien de l'interminable traité sur un sujet hautement technique, présente l'avantage évident de faire le tour complet du jardin. Il situe le travail de nuit dans son contexte très large de la contrainte sociale (police, sécurité, hôpitaux), des impératifs techniques (caractère contenu de certains processus physiques, chimiques ou opérationnels), économiques (maximisation des investissements) ou organisationnels (désir de croissance). Il débouche ensuite sur une analyse exhaustive des conséquences individuelles, professionnelles, familiales et sociales du travail de nuit, pour en dégager des «bilans circonstanciés», plus que des «jugements de valeur absolus» (p. 10).

Ces bilans mettent à contribution plusieurs disciplines et surtout, réexaminent le travail de nuit à la lumière des différentes recherches en laboratoire sur le sommeil, le rêve, les rythmes biologiques, etc.

Même si le lecteur est plus familier avec certains domaines de réflexion ou de recherche, il risque de découvrir de nouveaux travaux et surtout de voir apparaitre des liens qu'il n'avait pas prévus. De même, l'ouvrage ne se contente pas de procéder à des analyses exhaustives. Il débouche régulièrement sur des applications intéressantes, par exemple sur la façon d'organiser les horaires contenus, lorsqu'ils sont inévitables, pour minimiser les risques pour l'individu.

Pour terminer, rien ne saurait mieux décrire le ton et la profondeur d'analyse du volume de Carpentier et Cazamian que de citer quelques extraits de la conclusion: «Toute société industrielle engendre un conflit entre la volonté de produire et celle de protéger la production, entre la logique et l'économie et les exigences biopsychologiques des travailleurs, entre l'emprise de la croissance industrielle et la qualité de la vie individuelle et sociale... C'est dans cette perspective élargie d'une «écologie de l'homme au travail» qu'a été située la présente étude» (p. 71)

René BOULARD
The Current Industrial Relations Scene in Canada 1978, by W.D. Wood and Pradeep Kumar (Ed.), Kingston, Industrial Relations Centre, Queen's University, 1978, 693 pp.

Il nous a été donné de signaler à nos lecteurs la parution de cet annuaire publié par le Centre des relations industrielles de l'Université Queen (R.I., vol. 32, no. 3, p. 472). Cet ouvrage compréhensif contient la plupart des informations touchant les relations du travail au Canada.

L'édition de 1978 comprend les mêmes grandes rubriques: l'économie, la maind'œuvre et les marchés du travail, la législation du travail et la politique sociale, le syndicalisme, la négociation collective, les salaires, la productivité et les coûts de la main-d'œuvre, la documentation. Toutes les données ont été mises à jour et on a indiqué les changements intervenus au cours de l'année.

Des additions importantes ont été ajoutées qui ne se trouvaient pas dans l'édition précédente. Nous en soulignons quelquesunes: la liste de toute la législation du travail au Canada. Une attention particulière aux données par industrie et région, des notes techniques sur les sources d'information, etc.

Ainsi que nous l'avions dit, cet ouvrage est de nature à sauver beaucoup de temps à tous ceux qui veulent une information rapide et fiable. C'est un livre de chevet pour les professeurs, les chercheurs, les étudiants, les praticiens en relations du travail et les journalistes.

Gérard DION

Université Laval 